236

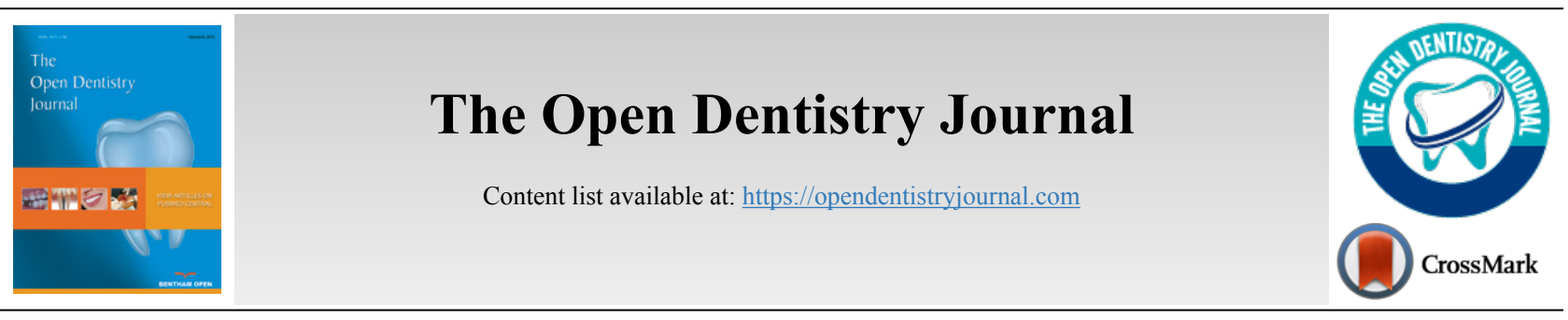

RESEARCH ARTICLE

\title{
Parents Knowledge and Awareness of their Children's Oral Health in Riyadh, Saudi Arabia
}

\author{
Abed A-H. Hamasha ${ }^{1,2, *}$, Salman J. Rasheed ${ }^{2}$, Mohammed M. Aldosari ${ }^{2}$ and Zainul Rajion ${ }^{3}$ \\ ${ }^{\prime}$ Department of Preventive Dentistry, Faculty of Dentistry, Jordan University of Science and Technology, Irbid22110, Jordan \\ ${ }^{2}$ Department of Preventive Dental Science, College of Dentistry, King Saud bin Abdulaziz University for Health Sciences, Riyadh11481, Saudi Arabia \\ ${ }^{3}$ School of Dental Sciences, USM Health Campus, Kubang Kerian, Kelantan, Malaysia
}

\begin{abstract}
:
Objective:

To assess the parents' knowledge and awareness of their children's oral health in Riyadh, Saudi Arabia.

Methods:

The study was a cross-sectional analytical study of Saudi parents. A self-administered questionnaire was collected from 324 parents in public parks and malls. In addition to the demographic questions, parents' knowledge about the number of primary teeth, tooth brushing, best time of dental visits, the meaning of plaque and calculus, the importance of fluoride, the relationship between primary and permanent teeth and the effect of oral health on general health were questioned. Data analysis included descriptive statistics and one-way analysis of variance and Bonferroni tests to assess differences in the mean number of correct answers among demographic categories. A $p$-value of 0.05 was set at a significant level.

Results:

The percentages of correct answers ranged from $26 \%$ to $75 \%$ depending on the type of questions. Only $26-28 \%$ could identify the number of primary teeth and the duration of teeth brushing. About one-third of parents knew the time of the first dental visit and the definition of plaque and calculus. Between $63-75 \%$ of parents believed that primary teeth can affect permanent teeth and mouth problems can affect general health. On average, $59.2 \%$ of participants provide incorrect answers about their children's oral health. The numbers of correct answers were significantly increased by increasing education and income.

\section{Conclusion:}

Parents' knowledge and awareness of oral health among Saudi parents were poor. Special attention should be given to parents with low socioeconomic status who need to be educated about children oral health more.
\end{abstract}

Keywords: Parent, Knowledge, Awareness, Oral health, Saudi, Demographic questions.

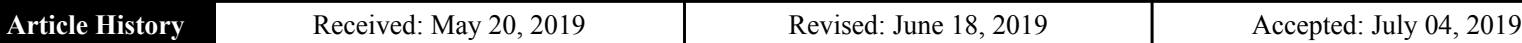

\section{INTRODUCTION}

The knowledge and awareness of parents of their children's oral health is a fundamental component that generates a preventive measure thus, leading to establishing a sound oral health status of their children [1]. Moreover, lack of parents' knowledge and awareness of their oral health will also affect their children future oral health attitudes and practices that they adopt which will be carried over into adulthood $[2,3]$.

\footnotetext{
* Address correspondence to this author at the Department of Preventive Dental Science, College of Dentistry, King Saud bin Abdulaziz University for Health Sciences P.O.Box.3660 Riyadh, 11426, KSA; Tel: 96611 4295725; E-mail: hamashaa@ksau-hs.edu.sa
}

It has been reported that a lack of parental awareness was an important indicator of children's poor oral hygiene [4].

Parents usually receive oral health care advices from their primary health care physicians, dentists, friends, and families. Parents usually ask specific questions about the time of teeth eruption, time of periodic visit for the dentist, time and frequency of tooth brushing, use of fluoride toothpaste and diet and sugar intake [5]. It had been reported that dental caries was higher among children whose parents lack awareness and knowledge of oral health [6].

Knowledge and awareness of children's oral health by 
parents were studied previously. In developing countries, many studies had reported poor parents' knowledge and awareness of oral health [2, 7 - 11]. However, other studies from industrialized countries revealed the opposite [12 - 14]. Searching the dental literature, no studies had evaluated the knowledge and awareness of Saudi parents related to their children's oral health. Therefore, this study was conducted to fill this knowledge gap. This study aims to assess parents' knowledge and awareness of their children's oral health in Riyadh, Saudi Arabia.

\section{MATERIALS AND METHODS}

The present study was a cross-sectional analytical study of Saudi parents who live in Riyadh City, Saudi Arabia. The proposal of this study was submitted to the Internal Review Board (IRB) committee of the King Abdullah International Medical Research Center, Saudi Arabia and an IRB for this research was obtained. The purpose of the study was explained to parents and consent forms were completed before answering the questions. The sampling procedure for this study was a convenient sampling of parents living in Riyadh city. Subjects were approached in the following public places: Alworood Park, Alrawdha Park, Panorama mall, and Altaawun Park. Inclusion criteria for this study comprised parents who had children. The exclusion criteria included non-Saudi individuals, children below 18 years of age, and adults with sons and daughters above 18 years of age.

A self-administered questionnaire was constructed in English and then translated to the Arabic Language as the population's formal language. Pilot samples of ten participants who were invited to answer the questionnaires were conducted one month before the commencement of the study. Participants comprehension of the questions and ambiguity related to their answers were discussed and cleared. Necessary corrections according to the outcome of the pilot study were accomplished before the start of the study.

The questionnaires were composed of 14 questions that were divided into two main subparts: 1) demographics including education, income, employment and number of their children. 2) Knowledge and awareness questions including a question about the number of primary teeth, tooth brushing, best time of dental visits, the meaning of plaque and calculus, the importance of fluoride, the relationship between primary and permanent teeth and the effect of oral health on general health (10 questions).

Questionnaires were distributed to participants and were instructed to answer all questions up to their best abilities. Members of the research team were presented with parents during filling questionnaires, so they are ready to answer any raised questions or concerns.

Data were entered and analyzed using the SPSS software version 23 (IBM Inc., Chicago, IL, USA). Data analysis included frequency distribution with numbers, percentages, means and standard deviations. In addition, one-way analysis of variance and Bonferroni tests to assess differences in the mean number of correct answers among demographic categories. A $p$-value of 0.05 was set at a significant level.

\section{RESULTS}

Of the 400 distributed questionnaires, a total number of 338 responses were received from participants. Of those, 14 questionnaires were excluded because of incomplete answers for the main knowledge and awareness questions. The final sample was 324 parents with an overall response rate of $81 \%$.

Table 1 presented the demographic characteristics of the study participants. About $44 \%$ of participants exhibited a college education or above and $21 \%$ of the sample were from the high-income category (Above Saudi Riyal (SR)20000). About half of the participants were employed by the government and only $9 \%$ were unemployed. Most families had one to three children, and about a third had more than three children.

Table 1. presented demographic characteristics of study participants.

\begin{tabular}{|c|c|c|c|c|c|}
\hline Variable & Category & No. & $\%$ & $\begin{array}{c}\text { Correct } \\
\text { Answers* }\end{array}$ & $\begin{array}{c}P \\
\text { Value*** }^{* *}\end{array}$ \\
\hline \multirow{4}{*}{$\begin{array}{c}\text { Level of } \\
\text { education }\end{array}$} & Primary school & 28 & 8.6 & 2.5357 & 0.000 \\
\hline & Intermediate school & 50 & 15.4 & 3.3000 & - \\
\hline & \begin{tabular}{|l|} 
High school \\
\end{tabular} & 105 & 32.4 & 3.7429 & - \\
\hline & College and above & 141 & 43.5 & 4.9078 & - \\
\hline \multirow{4}{*}{$\begin{array}{l}\text { Monthly } \\
\text { income }\end{array}$} & $<$ SR 4000 & 66 & 20.4 & 3.3939 & 0.021 \\
\hline & SR4000 - SR10,000 & 101 & 32.2 & 4.2376 & - \\
\hline & $\begin{array}{c}\text { SR10,000 - } \\
\text { SR20,000 }\end{array}$ & 88 & 27.2 & 4.2955 & - \\
\hline & $\begin{array}{l}\text { More than } \\
\text { SR20,000 }\end{array}$ & 69 & 21.3 & 4.2174 & - \\
\hline \multirow{4}{*}{ Occupation } & $\begin{array}{l}\text { Government } \\
\text { employee }\end{array}$ & 173 & 53.4 & 4.3006 & 0.119 \\
\hline & Private employee & 88 & 27.2 & 3.6932 & - \\
\hline & Self-employed & 33 & 10.2 & 4.1515 & - \\
\hline & Unemployed & 30 & 9.3 & 3.8333 & - \\
\hline \multirow{4}{*}{$\begin{array}{l}\text { Total } \\
\text { number of } \\
\text { children in } \\
\text { the family }\end{array}$} & One child & 80 & 24.7 & 4.0375 & 0.350 \\
\hline & Two children & 89 & 27.5 & 3.9438 & - \\
\hline & Three children & 57 & 17.6 & 4.5088 & - \\
\hline & $\begin{array}{l}\text { More than } 3 \\
\text { children }\end{array}$ & 98 & 30.2 & 3.9796 & - \\
\hline
\end{tabular}

* Mean number of correct answers out of 10 questions

** using a one-way analysis of variance.

Table 2 showed the frequency distribution of answers to the knowledge and awareness questions (10 questions). Only $26 \%$ could identify the number of primary teeth when all erupted. The ideal duration of brushing teeth as recommended by the American Dental Association (ADA [15] (2 minutes) was recognized by only $28 \%$ of participants and $43 \%$ answered the question about the regularity of changing toothbrush by individuals. About $33 \%$ of parents thought that the first dental visit of their children should be from six months to one year of age, however, about $42 \%$ described a dental visit to be at the age of six years and $14 \%$ believed that dental visits should be related to the children's complaints of pain. About $36 \%$ and $29 \%$ of participants could identify the definition of plaque and calculus, respectively. Moreover, more than $50 \%$ of parents believed that fluoride in toothpaste was not added for caries prevention and only $28 \%$ believed that plaque could cause 
gingivitis. Finally, about $63 \%$ of participants understood the effect of primary teeth problems on permanent teeth, and $75 \%$ believed that the oral health of the children had an effect on their general health.

Table 3 demonstrated the percentage of correct answers of
10 knowledge and awareness questions among participants. The percentages of correct answers ranged from $26 \%$ to $75 \%$ depending on the type of questions. On average, for the 10 questions, about $59.2 \%$ of participants provide incorrect answers about their children oral health.

Table 2. The frequency distribution of answers to the knowledge and awareness questions (10 questions).

\begin{tabular}{|c|c|c|c|c|c|}
\hline Question No. & Question Text & Category & No. & $\%$ & Answer \\
\hline \multirow{3}{*}{1} & \multirow{3}{*}{ What is the number of primary teeth when all erupted? } & 12 & 123 & 38.0 & Incorrect \\
\hline & & 16 & 116 & 35.8 & Incorrect \\
\hline & & 20 & 85 & 26.2 & Correct \\
\hline \multirow{4}{*}{2} & \multirow{4}{*}{ What is the ideal duration of brushing teeth? } & Few Seconds & 42 & 13.0 & Incorrect \\
\hline & & 1 minute & 116 & 35.8 & Incorrect \\
\hline & & 2 minutes & 91 & 28.1 & Correct \\
\hline & & 3 minutes & 75 & 23.1 & Incorrect \\
\hline \multirow{4}{*}{3} & \multirow{4}{*}{ How often do you change your child toothbrush } & Every 1 month & 65 & 20.1 & Incorrect \\
\hline & & Every 3 months & 138 & 42.6 & Correct \\
\hline & & Every 1 year & 95 & 29.3 & Incorrect \\
\hline & & No need to change it & 26 & 8.0 & Incorrect \\
\hline \multirow{4}{*}{4} & \multirow{4}{*}{ What is the best age for the first dental visit of your child? } & At birth & 36 & 11.1 & Incorrect \\
\hline & & 6 months -1 year of age & 106 & 32.7 & Correct \\
\hline & & After 6 years of age & 136 & 42.0 & Incorrect \\
\hline & & When feeling pain & 46 & 14.2 & Incorrect \\
\hline \multirow{3}{*}{5} & \multirow{3}{*}{ What does plaque mean } & Soft deposits & 118 & 36.4 & Correct \\
\hline & & Hard deposits & 89 & 27.5 & Incorrect \\
\hline & & I don't know & 117 & 36.1 & Incorrect \\
\hline \multirow{3}{*}{6} & \multirow{3}{*}{ What does calculus mean? } & Soft deposits & 140 & 43.2 & Incorrect \\
\hline & & Hard deposits & 94 & 29.0 & Correct \\
\hline & & I don't Know & 90 & 27.8 & Incorrect \\
\hline \multirow{4}{*}{7} & \multirow{4}{*}{ What is the importance of adding fluoride to toothpaste } & Prevent caries & 150 & 46.3 & Correct \\
\hline & & Whiten the teeth & 72 & 22.2 & Incorrect \\
\hline & & Clean the mouth & 39 & 12.0 & Incorrect \\
\hline & & I don't know & 63 & 19.4 & Incorrect \\
\hline \multirow{4}{*}{8} & \multirow{4}{*}{ How does the plaque affect the mouth? } & It causes gum disease & 91 & 28.1 & Correct \\
\hline & & It causes bad breath & 67 & 20.7 & Incorrect \\
\hline & & It causes discoloration & 66 & 20.4 & Incorrect \\
\hline & & I don't know & 100 & 30.9 & Incorrect \\
\hline \multirow{3}{*}{9} & \multirow{3}{*}{ Do primary teeth problems have an effect on permanent teeth } & Yes & 204 & 63.0 & Correct \\
\hline & & No & 48 & 14.8 & Incorrect \\
\hline & & I don't know & 72 & 22.2 & Incorrect \\
\hline \multirow{3}{*}{10} & \multirow{3}{*}{ Do you think that the oral health of the child affects his general health? } & Yes & 244 & 75.3 & Correct \\
\hline & & No & 32 & 9.9 & Incorrect \\
\hline & & I don't Know & 48 & 14.8 & Incorrect \\
\hline
\end{tabular}

Table 3. The percentage of correct answers of 10 knowledge and awareness questions among participants.

\begin{tabular}{|c|c|c|c|c|c|}
\hline \multirow{2}{*}{ No. } & \multirow{2}{*}{ Questions } & \multicolumn{2}{|c|}{ Correct Answer } & \multicolumn{2}{|c|}{ Incorrect Answer } \\
\hline & & No. & $\%$ & No. & $\%$ \\
\hline 1 & The number of primary teeth & 85 & 26.2 & 239 & 73.8 \\
\hline 2 & Ideal duration of tooth brushing & 91 & 28.1 & 233 & 71.9 \\
\hline 3 & The regularity of changing the toothbrush & 138 & 42.6 & 186 & 57.4 \\
\hline 4 & The best age for the first dental visit & 106 & 32.7 & 218 & 67.3 \\
\hline 5 & Meaning of plaque & 118 & 36.4 & 206 & 63.6 \\
\hline 6 & Meaning of calculus & 94 & 29.0 & 230 & 71.0 \\
\hline
\end{tabular}


(Table 3) contd.....

\begin{tabular}{|c|c|c|c|c|c|}
\hline \multirow{2}{*}{ No. } & \multirow{2}{*}{ Questions } & \multicolumn{2}{|c|}{ Correct Answer } & \multicolumn{2}{|c|}{ Incorrect Answer } \\
\hline & & No. & $\%$ & No. & $\%$ \\
\hline 7 & Importance of adding fluoride to toothpaste & 150 & 46.3 & 174 & 53.7 \\
\hline 8 & How Plaque effect gingiva & 91 & 28.1 & 233 & 71.9 \\
\hline 9 & Primary teeth affect permanent teeth & 204 & 63.0 & 120 & 37.0 \\
\hline 10 & Oral health affects general health & 244 & 75.3 & 80 & 24.7 \\
\hline Total & Total correct answers & 1321 & 40.8 & 1919 & 59.2 \\
\hline
\end{tabular}

Table 4. Post-hoc analysis of multiple comparisons of demographic characteristics against the dependent Variable: the total number of correct answers.

\begin{tabular}{|c|c|c|c|c|c|}
\hline \multirow{2}{*}{ Variable } & \multirow{2}{*}{ Level of Comparisons } & \multirow{2}{*}{ Mean Difference } & \multirow{2}{*}{$p$-value } & \multicolumn{2}{|c|}{ 95\% Confidence Interval } \\
\hline & & & & Lower & Upper \\
\hline \multirow{6}{*}{ Level of education } & Primary with intermediate & -.76429 & .486 & -1.9236 & .3950 \\
\hline & Primary with High school & $-1.20714^{*}$ & .014 & -2.2518 & -.1625 \\
\hline & Primary with College & $-2.37209^{*}$ & .000 & -3.3883 & -1.3559 \\
\hline & Intermediate with High school & -.44286 & .987 & -1.2868 & .4011 \\
\hline & Intermediate with College & $-1.60780^{*}$ & .000 & -2.4162 & -.7994 \\
\hline & High school with College & $-1.16494^{*}$ & .000 & -1.7981 & -.5318 \\
\hline \multirow{6}{*}{ Monthly income (SR) } & Less than 4000 with $4000-10000$ & $-.84368^{*}$ & .046 & -1.6782 & -.0092 \\
\hline & Less than 4000 with $10000-20000$ & $-.90152^{*}$ & .034 & -1.7600 & -.0430 \\
\hline & Less than 4000 with 20000 or more & -.82345 & .100 & -1.7312 & .0843 \\
\hline & $4000-10000$ with $10000-20000$ & -.05783 & 1.000 & -.8267 & .7110 \\
\hline & $4000-10000$ with 20000 or more & .02023 & 1.000 & -.8032 & .8437 \\
\hline & 10000-20000 with 20000 or more & .07806 & 1.000 & -.7697 & .9258 \\
\hline \multirow{6}{*}{ Occupation } & Government employee with Private employee & .60740 & .125 & -.0871 & 1.3019 \\
\hline & Government employee with Self-employed & .14906 & 1.000 & -.8585 & 1.1567 \\
\hline & Government employee with Unemployed & .46724 & 1.000 & -.5818 & 1.5163 \\
\hline & Private employee with Self-employed & -.45833 & 1.000 & -1.5411 & .6244 \\
\hline & Private employee with Unemployed & -.14015 & 1.000 & -1.2616 & .9813 \\
\hline & Unemployed with Self-employed & -.31818 & 1.000 & -1.6563 & 1.0199 \\
\hline \multirow{6}{*}{ Number of children } & 1 with 2 & .09368 & 1.000 & -.7268 & .9142 \\
\hline & 1 with 3 & -.47127 & 1.000 & -1.3944 & .4518 \\
\hline & 1 with more than 3 & .05791 & 1.000 & -.7446 & .8604 \\
\hline & 2 with 3 & -.56495 & .587 & -1.4684 & .3385 \\
\hline & 2 with more than 3 & -.03577 & 1.000 & -.8156 & .7440 \\
\hline & 3 with more than 3 & .52918 & .686 & -.3580 & 1.4163 \\
\hline
\end{tabular}

The mean number of correct answers and a p-value of the 10 knowledge and awareness questions among different demographic categories was presented in the right two columns of Table 1. The number of correct answers is significantly increased by increasing education from primary school ( 2.5 out of 10$)$ to college education (4.9 out of 10$)(p \leq 0.001)$. Similarly, the number of correct answers was increased significantly by increasing income $(p=0.021)$. No significant association was found been knowledge and awareness of oral health and neither occupation nor the number of children in the family. Table 4 presented Post-hoc analysis of multiple comparisons of demographic characteristics against the dependent variable: the total number of correct answers. The total number of correct answers varies significantly from having primary education compared to having a high school or a college education. Also, it varies significantly from intermediate education $v s$. college education or high school vs. college education. The number of correct answers was significantly different from those with less than SR4000 and those with either SR4000SR10000 or SR10000-SR20000 as monthly income.

\section{DISCUSSION}

The present study demonstrated the amount of knowledge and awareness that Saudi parents had in respect of their children oral health. However, the degree of knowledge and awareness of Saudi parents varied according to the type of questions asked. Less than $30 \%$ of parents could identify the number of primary teeth, the ideal duration of tooth brushing, the meaning of calculus and how plaque can affect the gingiva. Moreover, about two-thirds of parents could not provide an answer to the best age for the first dental visit and the meaning of plaque accumulated on teeth. However, two-thirds to threequarters of participants knew that their children's primary teeth can affect their permanent teeth, as well as oral health of children had an effect on children's general health. All over, 
only $40.8 \%$ could answer the given 10 questions correctly.

The sampling technique of this study was a convenient sampling procedure. There were difficulties in obtaining a random sampling procedure since there is no national listing of adults that can be reached, in addition, parents do not normally welcome research teams in their homes and do not have active participation in clubs or community centers. The best places parents and families can be approached in Riyadh city were either in public parks or malls. Therefore, we have chosen three public parks and one of the biggest malls in the city.

The knowledge and awareness about oral health among Saudi parents appeared to be poor. However, it is not different than many published studies [2, 7 - 11]. This indicated a need for an effective oral health educational program to be employed by parents. Educational programs through social media or campaigns might be an effective tool to enhance parents' awareness.

In the present study, we included parents' education and their socioeconomic status as factors affecting parental knowledge and awareness of oral health. These factors were reported by the previous studies $[16,17]$. Our study revealed that a lower level of education and low monthly income can affect parents' knowledge and awareness of their children's oral health negatively. In the present study, a significant association between the education levels of parents and their knowledge and awareness was observed. Therefore, parents' education might have a major impact on their children's oral health. Our results are in agreement with the findings in other studies the literature $[2,17$ - 20].

In this study, about $46 \%$ of parents could identify the importance of adding fluoride to toothpaste. These results were similar to a study by Sehrawat et al. (2016) [2] from India, who found that only $43 \%$ of the mothers knew that their toothpaste had fluoride. This result was contrasted by a study conducted by Jain et al. (2014) [20]. In our study, the appropriate interval of changing toothbrush (every 3 months) was answered correctly by only $43 \%$ of Saudi parents. These results are consistent with another study [21].

Many Saudi parents believed that the dental check-ups are not needed for children before six years of age (42\%), and only $33 \%$ answered the question of best age for the first dental visit correctly. These results were consistent with results obtained from dental patients who attended a Saudi dental college [8]. Other studies revealed similar results indicating that most parents were ignorant of the age of the first dental visit $[9,22]$.

\section{CONCLUSION}

Parents' knowledge and awareness of oral health among Saudi parents were relatively poor. Therefore, increasing the knowledge and awareness of parents about their children oral health can benefit the oral health status of their children. Special attention should be paid to parents' education and income which had a direct relationship to their awareness of their children oral health.

\section{ETHICS APPROVAL AND CONSENT TO PARTICIPATE}

Ethical approval was obtained from the IRB committee of King Abdullah Medical Research Center Saudi Arabia (SP18/4770/R).

\section{HUMAN AND ANIMAL RIGHTS}

No animals were used in this research. All research procedures followed were in accordance with the ethical standards of the committee responsible for human experimentation (institutional and national), and with the Helsinki Declaration of 1975, as revised in 2013 (http://ethics.iit. edu/ecodes/node/3931)?

\section{CONSENT FOR PUBLICATION}

All participants signed the study consent before answering the questions.

\section{AVAILABILITY OF DATA AND MATERIALS}

The data sets analyzed during the current study are available from the corresponding author (Abed A-H. Hamasha) on request.

\section{FUNDING}

None.

\section{CONFLICT OF INTEREST}

The authors declare no conflict of interest, financial or otherwise.

\section{ACKNOWLEDGMENTS}

Declared none.

\section{REFERENCES}

[1] Okada M, Kawamura M, Kaihara Y, et al. Influence of parents' oral health behaviour on oral health status of their school children: An exploratory study employing a causal modelling technique. Int $\mathrm{J}$ Paediatr Dent 2002; 12(2): 101-8.

[http://dx.doi.org/10.1046/j.1365-263X.2002.00338.x] [PMID: 11966 888]

[2] Sehrawat P, Shivlingesh KK, Gupta B, Anand R, Sharma A, Chaudhry $M$. Oral health knowledge, awareness and associated practices of preschool children's mothers in Greater Noida, India. Niger Postgrad Med J 2016; 23(3): 152-7.

[http://dx.doi.org/10.4103/1117-1936.190344] [PMID: 27623728]

[3] Guidelines on Oral Healthcare for Pre-School Children. Oral Health Division Ministry of Health Malaysia. https://www.mah.se/upload/ FAKULTETER/OD/Avdelningar/who/WPRO/Malaysia/data/oral_heal thcare_for_the_pre-school_children.pdf

[4] Vanagas G, Milasauskiene Z, Grabauskas V, Mickeviciene A. Associations between parental skills and their attitudes toward importance to develop good oral hygiene skills in their children. Medicina (Kaunas) 2009; 45(9): 718-23.

[http://dx.doi.org/10.3390/medicina45090094] [PMID: 19834309]

[5] Felton A, Chapman A, Felton S. Basic Guide to oral health education and promotion, $2^{\text {nd }}$ ed. john wiley \& sons, Ltd, The Atrium, Southern Gate, Chichester, West Sussex, PO19 8SQ, UK.

[6] Amin TT, Al-Abad BM. Oral hygiene practices, dental knowledge, dietary habits and their relation to caries among male primary school children in Al Hassa, Saudi Arabia. Int J Dent Hyg 2008; 6(4): 361-70. [http://dx.doi.org/10.1111/j.1601-5037.2008.00310.x] [PMID: 19138 188]

[7] Chhabra N, Chhabra A. Parental knowledge, attitudes and cultural beliefs regarding oral health and dental care of preschool children in 
an Indian population: A quantitative study. Eur Arch Paediatr Dent 2012; 13(2): 76-82.

[http://dx.doi.org/10.1007/BF03262848] [PMID: 22449806]

[8] Al-Shalan TA, Al-Musa BA, Al-Khamis AM. Parents' attitude towards children's first dental visit in the College of Dentistry, Riyadh, Saudi Arabia. Saudi Med J 2002; 23(9): 1110-4.

[PMID: 12370724]

[9] Nazari Z, Taherpour M. mothers' Awareness, regarding orodental health of their children at age of 16 years old in Shirvan. J North Khorasan Univ Med Sci 2013; 5: 979-86.

[10] Prabhu A, Rao AP, Reddy V, Ahamed SS, Muhammad S, Thayumanavan S. Parental knowledge of pre-school child oral health. J Community Health 2013; 38(5): 880-4.

[http://dx.doi.org/10.1007/s10900-013-9693-x] [PMID: 23624797]

[11] Alyahya L. Parental knowledge and practices regarding their children's oral health in Kuwait. Eur J Paediatr Dent 2016; 17(4): 267-73.

[PMID: 28045313]

[12] Chia L, Densie I, Morgan C. An exploratory study of parental knowledge of early childhood oral health care in Southland, New Zealand. N Z Dent J 2015; 111(1): 18-24. [PMID: 25845057]

[13] Wapniarska K, Buła K, Hilt A. Parent's pro-health awareness concerning oral health of their children in the light of survey research. Przegl Epidemiol 2016; 70(1): 59-63, 137-140.

[PMID: 27344476]

[14] Laganà G, Abazi Y, Beshiri Nastasi E, et al. Oral health conditions in an Albanian adolescent population: An epidemiological study. BMC Oral Health 2015; 15: 67.

[http://dx.doi.org/10.1186/s12903-015-0050-6] [PMID: 26072054]
[15] Mouth Healthy TM. Brought to you by the ADA American Dental Association.. Accessed on May 07 2019.https://www.mouthhealthy. org/en/az-topics/b/brushing-your-teeth

[16] Goodman HS, Macek MD, Wagner ML, Manz MC, Marrazzo ID. Self-reported awareness of unrestored dental caries. Survey of the oral health status of maryland schoolchildren, 2000--2001. Pediatr Dent 2004; 26(4): 369-75. [PMID: 15344634]

[17] Shaghaghian S, Savadi N, Amin M. Evaluation of parental awareness regarding their child's oral hygiene. Int J Dent Hyg 2017; 15(4): e149-55.

[http://dx.doi.org/10.1111/idh.12221] [PMID: 27113969]

[18] Mishra A, Pandey RK, Chopra H, Arora V. Oral health awareness in school-going children and its significance to parent's education level. J Indian Soc Pedod Prev Dent 2018; 36(2): 120-4.

[http://dx.doi.org/10.4103/JISPPD.JISPPD_1172_17] [PMID: 29970 627]

[19] Isong IA, Zuckerman KE, Rao SR, Kuhlthau KA, Winickoff JP, Perrin JM. Association between parents' and children's use of oral health services. Pediatrics 2010; 125(3): 502-8.

[http://dx.doi.org/10.1542/peds.2009-1417] [PMID: 20123775]

[20] Jain R, Oswal KC, Chitguppi R. Knowledge, attitude and practices of mothers toward their children's oral health: A questionnaire survey among subpopulation in Mumbai (India). J Dent Res Sci Dev 2014; 1: $40-5$.

[http://dx.doi.org/10.4103/2348-3407.135073]

[21] Tomarian L, Rahimluii BA. Parental awareness of oral hygiene status in 7 year old children, Tehran-1996. J Dent Sch 2001; 19: 125-34.

[22] Naderifar M, Akbarsharifi T, Pairovi H, Haghani H. Mothers' awareness, regarding orodental health of their children at age of 16 years old. Iran J Nurs 2006; 19: 15-27.

(C) 2019 Hamasha et al.

This is an open access article distributed under the terms of the Creative Commons Attribution 4.0 International Public License (CC-BY 4.0), a copy of which is available at: (https://creativecommons.org/licenses/by/4.0/legalcode). This license permits unrestricted use, distribution, and reproduction in any medium, provided the original author and source are credited. 